\title{
Keggin-Type Heteropolyacid for Ring-Opening Polymerization of Cyclohexene Oxide: Molecular Weight Control
}

\author{
Ahmed Aouissi, ${ }^{1}$ Zeid Abdullah Al-Othman, ${ }^{1}$ and Abdurrahman Salhabi ${ }^{2}$ \\ ${ }^{1}$ Department of Chemistry, College of Science, King Saud University, P.O. Box 2455, Riyadh 11451, Saudi Arabia \\ ${ }^{2}$ King Abdulaziz City for Science and Technology, P.O. Box 6086, Riyadh 11442, Saudi Arabia \\ Correspondence should be addressed to Ahmed Aouissi; aouissed@yahoo.fr
}

Received 20 April 2015; Accepted 7 June 2015

Academic Editor: Jose Ramon Leiza

Copyright (C) 2015 Ahmed Aouissi et al. This is an open access article distributed under the Creative Commons Attribution License, which permits unrestricted use, distribution, and reproduction in any medium, provided the original work is properly cited.

Polymerization of 1,2-cyclohexene oxide $(\mathrm{CHO})$ in dichloromethane was catalyzed by 12-tungstophosphoric acid $\left(\mathrm{H}_{3} \mathrm{PW}_{12} \mathrm{O}_{40} \cdot 13 \mathrm{H}_{2} \mathrm{O}\right)$ as a super solid acid. The effect of polymerization parameters such as reaction time, temperature, and catalyst amount was investigated. The effect of acetic anhydride as a ring-opening agent was also investigated. The resulting poly(1,2-cyclohexene oxide) (PCHO) was characterized by Fourier transform infrared (FTIR), nuclear magnetic resonance spectroscopy ( $\left.{ }^{1} \mathrm{HNMR}\right)$, gel-permeation chromatography (GPC), and differential scanning calorimetry (DSC). It has been found that the PCHO prepared over $\mathrm{H}_{3} \mathrm{PW}_{12} \mathrm{O}_{40} \cdot 13 \mathrm{H}_{2} \mathrm{O}$ has a stereoregularity higher than that prepared over clay and Aluminium alkoxide catalysts. The $T_{\mathrm{g}}$ value obtained is due to the microstructure but not to molecular weight. The yield and the molecular weight of the polymer depend strongly on the reaction conditions. Molecular weights can be readily controlled by changing reaction temperature, reaction time, and catalyst amount. Contrary to most polymerization reactions, the molecular weight increases with the temperature increase. Addition of acetic anhydride to the reaction medium increased the yield threefold.

\section{Introduction}

Due to their high polarizability and flexibility, polyethers constitute a very important soft segment for producing thermoplastic elastomers. Many of these polymers have been synthesized by ring-opening polymerization (ROP) of cyclic ether monomers [1]. Among cyclic monomers' ring-opening polymerization that of cyclohexene oxide (epoxide) into polycyclohexene oxide (polyether) has been the subject of a large number of papers [2-5]. This is due to the fact that cyclohexene oxide (CHO) polymers are useful materials. In fact, they are used in the synthesis of various alicyclic target materials including pesticides, pharmaceuticals, perfumery, and dyestuffs. ROP of cyclic ethers could be initiated by electrophilic agents such as Brønsted acids $\left(\mathrm{HCl}, \mathrm{H}_{2} \mathrm{SO}_{4}\right.$, $\mathrm{HClO}_{4}$, etc. $)$ and Lewis acids $\left(\mathrm{AlCl}_{3}, \mathrm{BF}_{3} \mathrm{OEt}_{2}, \mathrm{TiCl}_{4}\right.$, etc. $)$. However, the protonic acid catalysts used are corrosive and not recoverable, and the Lewis acids required great amount to achieve acceptable polymer yields. Because of increasing environmental concerns in recent years, a more effective catalytic process has been sought. In this respect, researchers have conducted studies on the development of solid acids so that aggressive and dangerous homogeneous acids can be replaced to overcome the problem of separating the catalysts from the products and from the disposal of solid/liquid waste. Solid Brønsted acids with super acidic character, such as the Keggin-type heteropolyacids, are known as highly active catalysts [6-8]. Due to their strong acidity, these "super acids" catalyze various reactions much more effectively than the conventional protonic acids $[9,10]$. In recent years, heteropolyacids have been used as catalysts to induce the polymerization of various monomers such as cyclic ethers, styrene, acetals, polyalcohols, and lactones [11-13]. In a previous paper [14] we have reported the polymerization of tetrahydrofuran catalyzed by a series of heteropolyacids. It has been found that $\mathrm{H}_{3} \mathrm{PW}_{12} \mathrm{O}_{40}$ was the efficient catalyst of the series of heteropolyacids tested. This fact prompted us to investigate the cationic ring-opening polymerization of $\mathrm{CHO}$ 
by this catalyst. The effect of reaction temperature, reaction time, catalyst amount, and acetic anhydride proportion on the polymerization was investigated.

\section{Materials and Methods}

2.1. Catalyst Preparation. $\mathrm{H}_{3} \mathrm{PW}_{12} \mathrm{O}_{40}$ was prepared according to a now well-known method [15]; that is, $100 \mathrm{~g}$ of $\mathrm{Na}_{2} \mathrm{WO}_{4} \cdot 2 \mathrm{H}_{2} \mathrm{O}$ was dissolved in $100 \mathrm{~mL}$ of warm distilled water and then successively $85 \% \mathrm{H}_{3} \mathrm{PO}_{4}(5 \mathrm{~mL})$ and $37.5 \%$ $\mathrm{HCl}(22 \mathrm{~mL})$ were added slowly to the solution. The mixture was concentrated to three quarters of its initial volume by heating and then after that it was cooled to room temperature. The cooled mixture was extracted with diethyl ether in hydrochloric acid medium. The product formed with ether, which settled down at the bottom, was separated from the aqueous phase. The white crystals of $\mathrm{H}_{3} \mathrm{PW}_{12} \mathrm{O}_{40} \cdot 13 \mathrm{H}_{2} \mathrm{O}$ were dried at room temperature.

2.2. Polymerization Procedure. Polymerization reactions of $\mathrm{CHO}$ were carried out in dichloromethane in a glass reactor fitted with a condenser. The temperature of the reactor was adjusted by a heating jacket. Typically, a fixed amount of $\mathrm{H}_{3} \mathrm{PW}_{12} \mathrm{O}_{40}$ as catalyst was added to $\mathrm{CHO}(10 \mathrm{~mL})$ and dichloromethane $(4 \mathrm{~mL})$ mixture under stirring at a desired temperature. Polymerization was terminated with addition of a saturated $\mathrm{NaOH}$ aqueous solution and still stirred for $5 \mathrm{~min}$. At the end of the reaction, the resulting $\mathrm{PCHO}$ polymer was precipitated in methanol and then filtrated off for characterization and molecular weight measurements.

2.3. Catalyst and Polymer Characterization. The Keggin structure of the catalyst $\left(\mathrm{H}_{3} \mathrm{PW}_{12} \mathrm{O}_{40}\right)$ was checked by means of FTIR. IR spectrum was recorded with an infrared spectrometer GENESIS II FTIR $\left(4000-400 \mathrm{~cm}^{-1}\right)$ as $\mathrm{KBr}$ pellets.

The polymer was characterized by using FTIR spectroscopy, NMR spectroscopy, differential scanning calorimeter (DSC), and molecular weight measurements. ${ }^{1} \mathrm{H}$ NMR spectra were recorded on a Bruker Avance $400 \mathrm{MHz}$ spectrophotometer using $5 \mathrm{~mm}$ NMR tubes using deuterated acetone-D6 as solvent. DSC model DSC-60 made by Shimadzu was utilized here. The specimens weigh about $12 \mathrm{mg}$ each. Each specimen was placed in aluminum pan. The pan was placed in the DSC's oven in air at atmospheric pressure. Specimens were heated at a constant heating rate of $5^{\circ} \mathrm{C} / \mathrm{min}$ to $300^{\circ} \mathrm{C}$. Molecular weight measurements were determined by means of a HT-GPC, Model 430, Viscotek, Houston, TX, USA, gel-permeation chromatograph (GPC) with CLM6210 column.

\section{Results and Discussion}

3.1. Characterization of the Catalyst. Infrared spectrum of $12-$ tungstophosphoric acid, $\mathrm{H}_{3} \mathrm{PW}_{12} \mathrm{O}_{40} \cdot 13 \mathrm{H}_{2} \mathrm{O}$ (abbreviated as $\mathrm{H}_{3} \mathrm{PW}_{12} \mathrm{O}_{40}$ ), is shown in Figure 1. According to [16], the main characteristic features of the Keggin structure observed at $1080-1060 \mathrm{~cm}^{-1}\left(\nu_{\mathrm{as}} \mathrm{P}-\mathrm{O}_{\mathrm{a}}\right)$, at $990-960 \mathrm{~cm}^{-1}\left(\nu_{\mathrm{as}} \mathrm{Mo}-\mathrm{O}_{\mathrm{d}}\right)$,

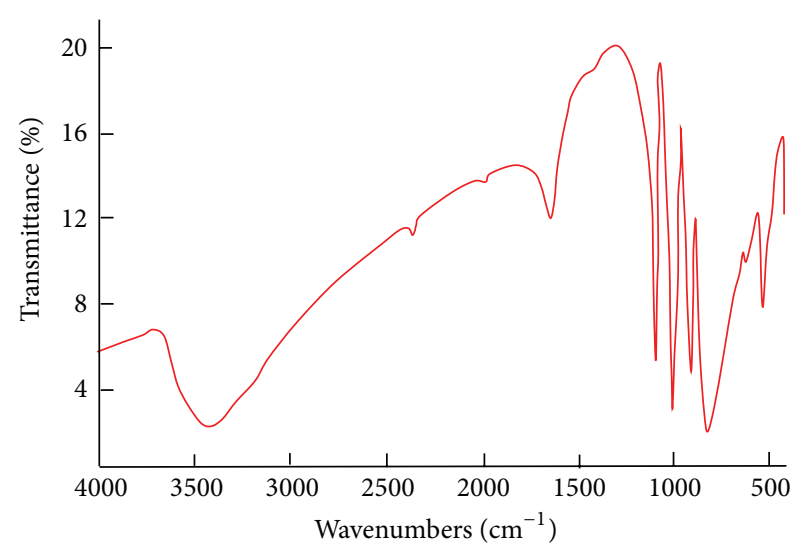

Figure 1: IR spectrum of $\mathrm{H}_{3} \mathrm{PW}_{12} \mathrm{O}_{40}$.

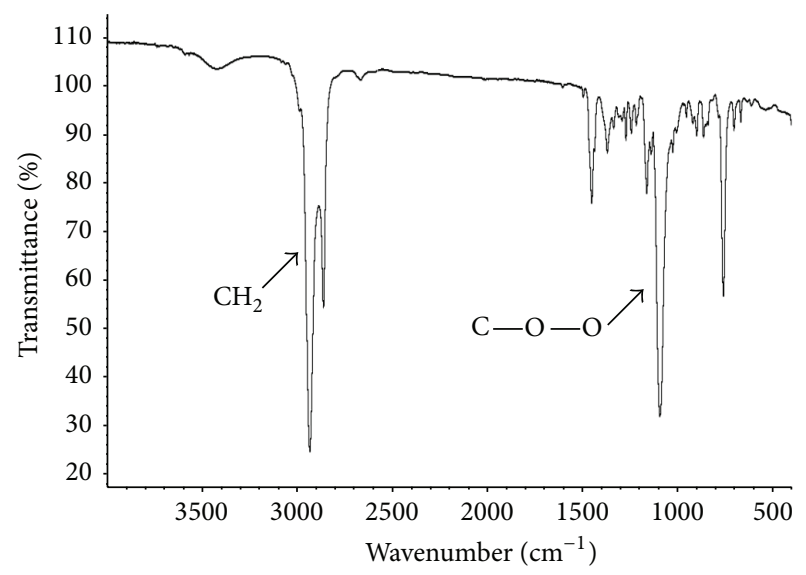

FIgUre 2: IR spectrum of poly(CHO). Polymerization catalyzed by $0.2 \mathrm{~g}$ of $\mathrm{H}_{3} \mathrm{PW}_{12} \mathrm{O}_{40}$ at $40^{\circ} \mathrm{C}$ during 3 hours in $\mathrm{CH}_{2} \mathrm{Cl}_{2}$.

at $900-870 \mathrm{~cm}^{-1}\left(\nu_{\mathrm{a}} \mathrm{Mo}-\mathrm{O}_{\mathrm{d}}-\mathrm{Mo}\right)$, and at $810-760 \mathrm{~cm}^{-1}\left(\nu_{\text {as }}\right.$ Mo- $\left.\mathrm{O}_{\mathrm{c}}-\mathrm{Mo}\right)$ were obtained.

3.2. Polymer Characterization. The cationic ring-opening polymerization of cyclohexene oxide was catalyzed by $\mathrm{H}_{3} \mathrm{PW}_{12} \mathrm{O}_{40}$ solid super acid catalyst in dichloromethane at $40^{\circ} \mathrm{C}$ (Scheme 1).

The IR spectrum of $\mathrm{PCHO}$ is shown in Figure 2. The bands present at $2932\left(\gamma_{\mathrm{as}} \mathrm{CH}_{2}\right), 2859\left(\gamma_{\mathrm{s}} \mathrm{CH}_{2}, \gamma \mathrm{CH}\right), 1449$ $\left(\delta \mathrm{CH}_{2}\right), 1366\left(\delta \mathrm{CH}_{2}\right), 1158,1090(\mathrm{C}-\mathrm{O}-\mathrm{C}$ antisymmetric stretching), 895,850 , and 756 ( $\delta \mathrm{CH}$ out-of-plane). These assignments for PCHO agree well with those of Yahiaoui et al. [2] and Suga and Aoyama [17] for the PCHO prepared with an acid-exchanged montmorillonite clay catalyst.

Figure 3 shows different peaks, the methylene groups (cyclohexane $\mathrm{CH}_{2}{ }^{-}$) at $1.0-2.0 \mathrm{ppm}$, and methine groups $\left(\mathrm{CH}_{2}-\mathrm{CHO}\right)$ at $3.2-3.6 \mathrm{ppm}$. The signal of the methine protons appears in the form of two peaks (3.28 and $3.33 \mathrm{ppm}$ ), which we attribute, respectively, to triads isotactic $(\mathrm{mm})$ and heterotactic ( $\mathrm{mr}$ and $\mathrm{rm}$ ). These assignments for $\mathrm{PCHO}$ agree well with those of Ling et al. [5] for the PCHO prepared over recyclable scandium triflate in room temperature ionic liquid catalyst. 


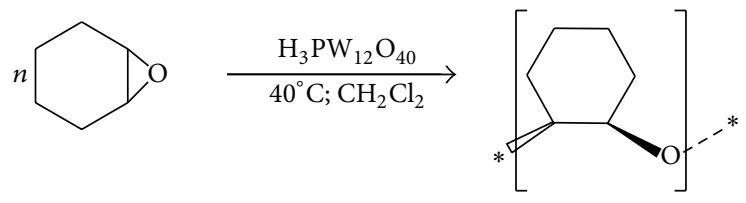

SCHEME 1: Reaction scheme for the synthesis of PCHO by ring-opening polymerization of CHO over $\mathrm{H}_{3} \mathrm{PW}_{12} \mathrm{O}_{40}$ catalyst.

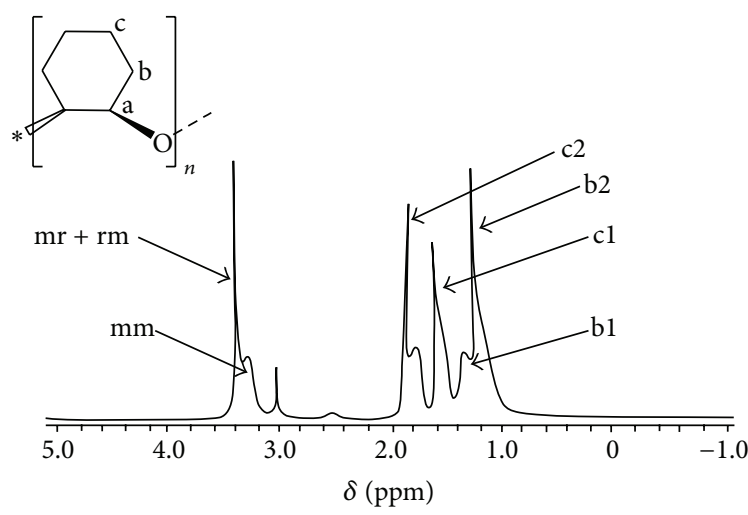

Figure $3:{ }^{1} \mathrm{HNMR}$ spectrum of PCHO. Polymerization catalyzed by $0.2 \mathrm{~g}$ of $\mathrm{H}_{3} \mathrm{PW}_{12} \mathrm{O}_{40} \cdot 13 \mathrm{H}_{2} \mathrm{O}$ at $40^{\circ} \mathrm{C}$ during 3 hours in $\mathrm{CH}_{2} \mathrm{Cl}_{2}$.

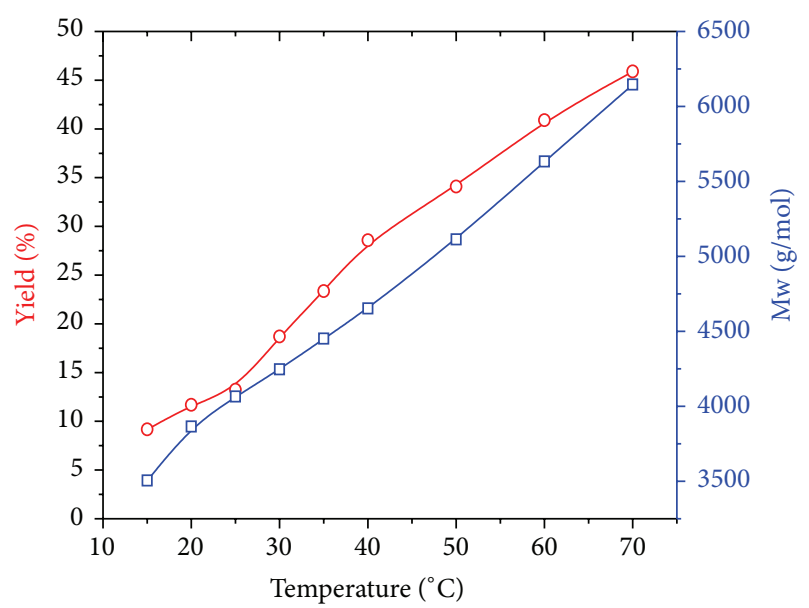

FIGURE 4: Yield and $\mathrm{Mw}$ of $\mathrm{PCHO}$ as a function of reaction temperature. Polymerization catalyzed by $0.2 \mathrm{~g}$ of $\mathrm{H}_{3} \mathrm{PW}_{12} \mathrm{O}_{40}$ during 3 hours in $\mathrm{CH}_{2} \mathrm{Cl}_{2}$.

3.3. Effect of Reaction Temperature. The effect of the reaction temperature on the yield, molecular weight, and $T_{\mathrm{g}}$ of the $\mathrm{PCHO}$ was investigated. The reactions were carried out in a temperature ranging from $15^{\circ} \mathrm{C}$ to $70^{\circ} \mathrm{C}$ in dichloromethane solvent. Figure 4 shows the effect of the temperature on the yield and on the molecular weight. It can be seen that both the yield and the molecular weight increased with the increase of the temperature. This result is in agreement with that reported in the literature [2]. The increase of the yield with temperature is an expected result but the increase of the molecular weight is unexpected. In fact, in most polymerization reactions, the molecular weight decreases

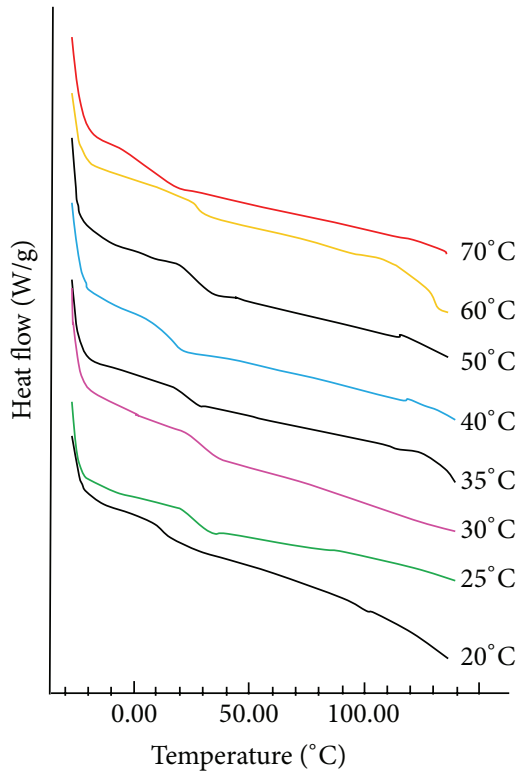

FIGURE 5: Typical DSC thermograms of the prepared PCHO obtained at a heating rate of $20^{\circ} \mathrm{C} / \mathrm{min}$. Polymerization catalyzed by $0.2 \mathrm{~g}$ of $\mathrm{H}_{3} \mathrm{PW}_{12} \mathrm{O}_{40}$ during 3 hours in $\mathrm{CH}_{2} \mathrm{Cl}_{2}$.

with the increase of the temperature owing to the fact that the temperature accelerates the rate of chain transfer reactions which in turn decreases the molecular weight [18]. In the case of $\mathrm{CHO}$ polymerization, the increase of the molecular weight can be explained by the fact that the HO- group bound to a rigid cyclohexene ring cannot approach sufficiently close to the oxygen atom to allow for the interchange reaction [19].

The effect of the temperature reaction on the PCHO $T_{\mathrm{g}}$ is shown in Figure 5. It can be seen that the $T_{\mathrm{g}}$ values are ranging between 23 and $37^{\circ} \mathrm{C}$. These $T_{\mathrm{g}}$ values are different from that observed by Yahiaoui et al. $\left(T_{\mathrm{g}}=75.23^{\circ} \mathrm{C}\right)$ over a clay catalyst [2]. As for the $\mathrm{PCHO}$ prepared by Zevaco et al. over Aluminium alkoxides catalyst [20], the authors reported that they have not observed a clear glass transition temperature but a broad endotherm between 66 and $100^{\circ} \mathrm{C}$ $\left(\max\right.$ at $70^{\circ} \mathrm{C}$ ) which they have attributed to a melting point of their resulting polymer. The difference in the $T_{\mathrm{g}}$ value between our polymer and that of Yahiaoui et al. and Zevaco et al. might be due to the difference in the microstructure of the prepared polymer. Indeed, our PCHO which was prepared by a super acid (Keggin heteropolyacid) has a different stereoregularity than that prepared by these authors. In fact, the ${ }^{1} \mathrm{H}$ NMR spectrum of our PCHO showed only two peaks ( 3.28 and $3.33 \mathrm{ppm}$ ) for the signals of the methine 


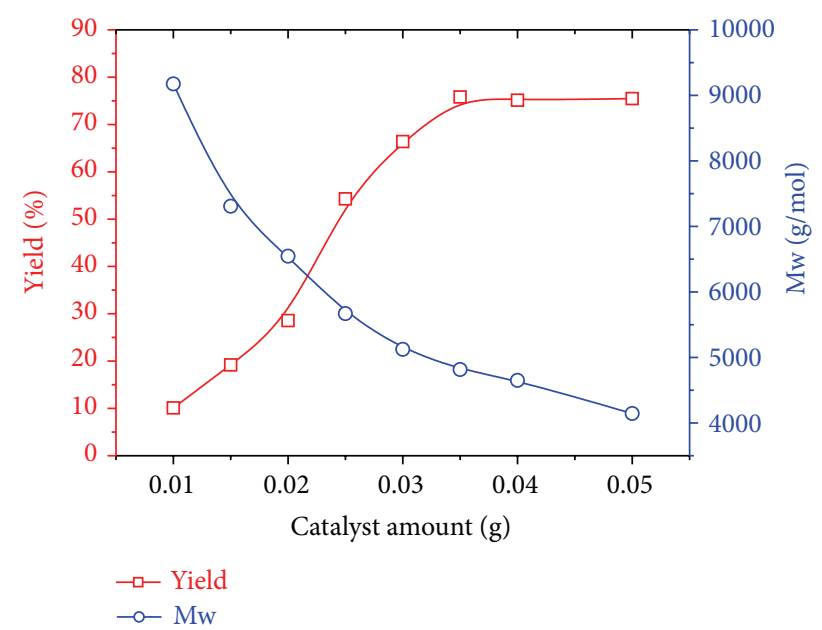

FIGURE 6: Effect of catalyst amount on the molecular weight and yield for the polymerization of $\mathrm{CHO}$ in $\mathrm{CH}_{2} \mathrm{Cl}_{2}$ at $40^{\circ} \mathrm{C}$ over $\mathrm{H}_{3} \mathrm{PW}_{12} \mathrm{O}_{40}$.

protons which we have attributed, respectively, to triads isotactic $(\mathrm{mm})$ and heterotactic $(\mathrm{mr}$ and $\mathrm{rm})$ whereas the NMR of the PCHO prepared by Yahiaoui et al. [2] and Zevaco et al. [20] showed three peaks $(3.3,3.4$, and $3.5 \mathrm{ppm})$ and $(3.66,3.78$, and $3.88 \mathrm{ppm})$, respectively, which they attribute, respectively, to triads isotactic $(\mathrm{mm})$, heterotactic $(\mathrm{mr}$ and $\mathrm{rm}$ ), and syndiotactic ( $\mathrm{rr}$ ).

3.4. Effect of Catalyst Amount. To investigate the effect of the amount of catalyst on the polymerization yield and molecular weight, we carried out the polymerization reaction of $\mathrm{CHO}$ $(10 \mathrm{~mL})$ in dichloromethane $(4 \mathrm{~mL})$ at $40^{\circ} \mathrm{C}$ during 3 hours. The results obtained are reported in Figure 6 . It can be seen that the polymer yield increases as the mass of the catalyst increases, whereas the molecular weight decreases. The highest molecular weight $\left(9100 \mathrm{~g} \mathrm{~mol}^{-1}\right)$ was obtained for the lowest amount used of catalyst $(10 \mathrm{mg})$. The inverse proportionality between the molecular weight and the amount of catalyst can be explained by the fact that when the amount of the catalyst increased, the number of initiating active responsible sites $\left(\mathrm{H}^{+}\right)$for inducing polymerization increased and consequently the number of chains increased which is obviously at the expense of the length of the chains. The decrease in molecular weight might be due also to the increase in water which increased with the increase of catalyst amount.

3.5. The Effect of Reaction Time. Effect of reaction time on the yield and the molecular weight of the polymer were examined. The polymerization reactions were catalyzed by $0.02 \mathrm{~g}$ of catalyst at $40^{\circ} \mathrm{C}$ in dichloromethane solvent. The results (Figure 7) show that both the yield and molecular weight of the polymer increase with increasing reaction time. The increase of the yield and the molecular weight was rapid for short reaction times whereas for long time reactions a slight variation is observed. A yield of $64 \%$ and a molecular

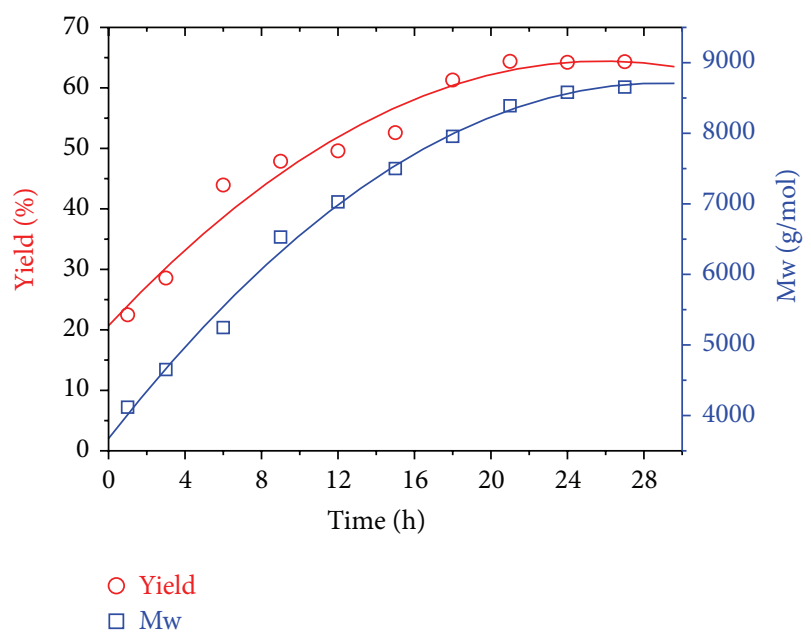

FIGURE 7: Effect of reaction time on the conversion and molecular weight of $\mathrm{PCHO}$ in $\mathrm{CH}_{2} \mathrm{Cl}_{2}$ at $40^{\circ} \mathrm{C}$ over $\mathrm{H}_{3} \mathrm{PW}_{12} \mathrm{O}_{40}$.

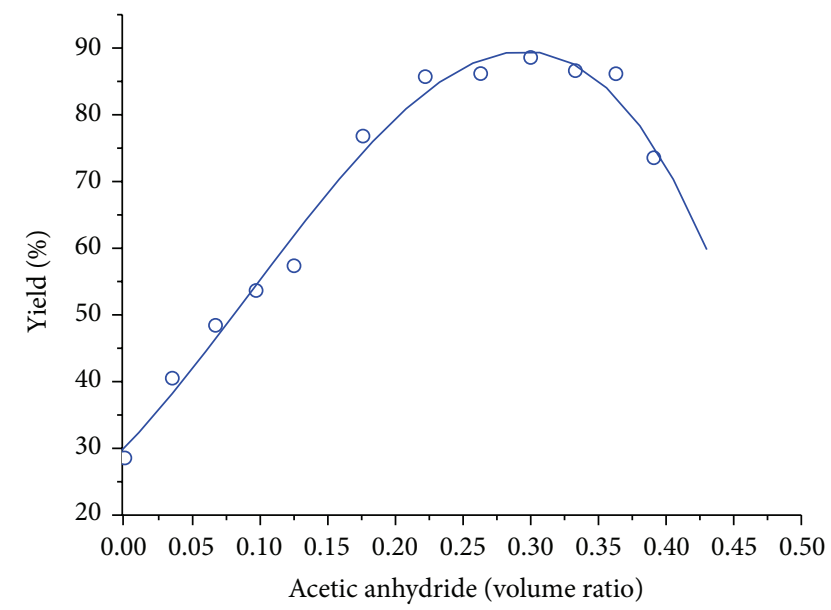

FIGURE 8: Effect of acetic anhydride proportion on PCHO yield. Reaction conditions: $T=40^{\circ} \mathrm{C}$; reaction time $=3 \mathrm{~h}$.

weight of $8300 \mathrm{~g} \mathrm{~mol}^{-1}$ are reached after 21 hours of reaction. The stagnation of the molecular mass may be due to the fact that, at higher yields and higher molecular weights, the viscosity of the medium increased and therefore the reaction became kinetically slow. So there was a stagnation of the molecular weight and yield.

3.6. Effect of Acetic Anhydride Proportion. Acetic anhydride has been used for the ring-opening of many heterocyclic compounds and it has been found that the yield of the polymer depends on its used proportion [21-23]. That is why we have tried to study its effect on the ring-opening of $\mathrm{CHO}$. To achieve this, different volumes are added to the solution $\mathrm{CHO} / \mathrm{CH}_{2} \mathrm{Cl}_{2}$. The reactions were carried out at $40^{\circ} \mathrm{C}$ for three hours. The results obtained (Figure 8) showed that the yield of the polymer depends strongly on the acetic anhydride proportion. In fact, when the volume ratio varies from 0 to 


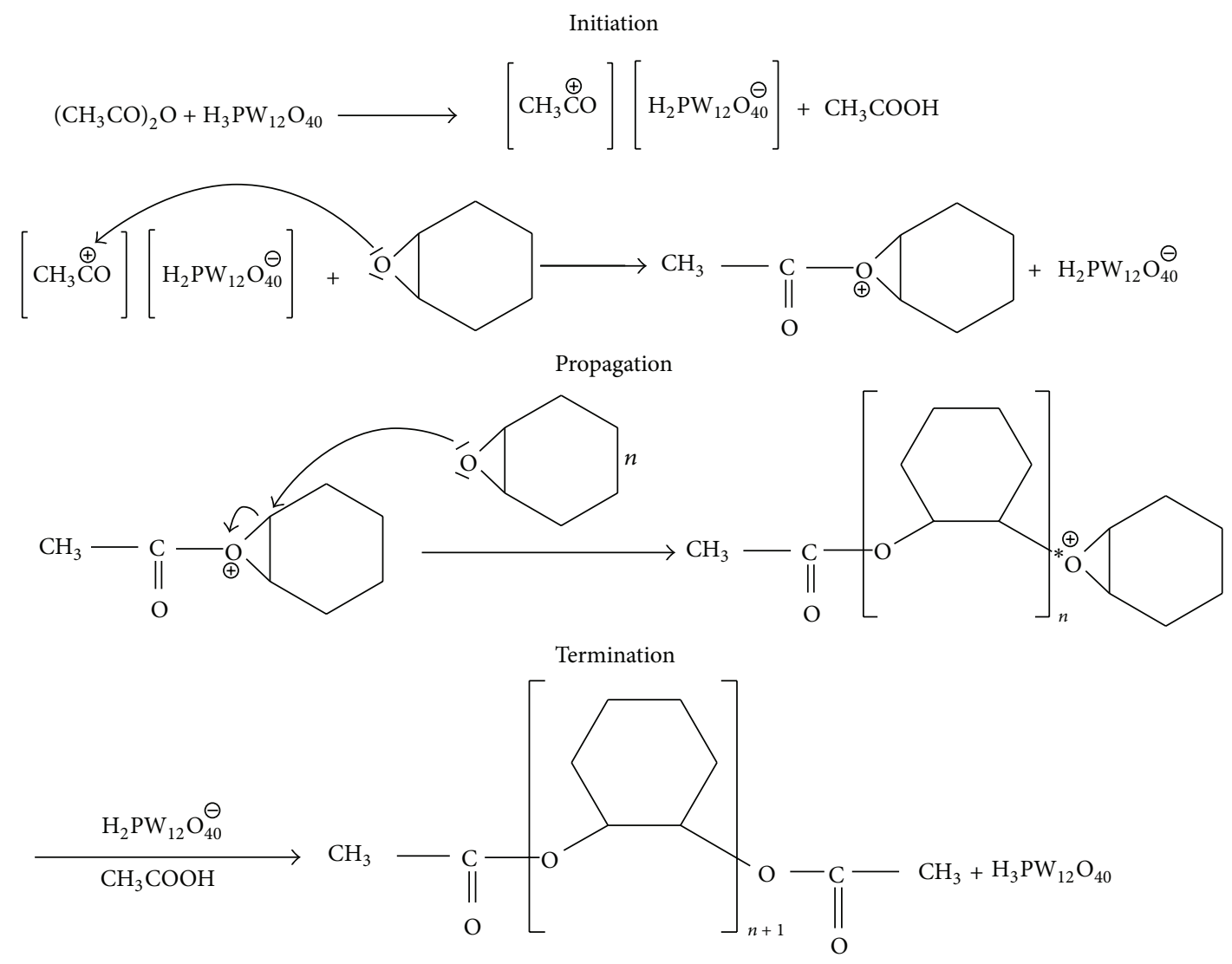

Scheme 2: Mechanism for the ring-opening polymerization of cyclohexene oxide in the presence of acetic anhydride over $\mathrm{H}_{3} \mathrm{PW}_{12} \mathrm{O}_{40}$ catalyst.

0.30 , the yield increased by $20 \%$ to $60 \%$. This shows that the initial value has tripled. When the volume ratio of the acetic anhydride added is beyond 0.3 , the yield decreased. The decrease of the yield at high acetic anhydride volume ratio might be due to consumption of heteropolyacid protons by the acetic anhydride leading to acetic acid (a weak acid) or to an increase in the number of methyl groups at the extremities of the chains that block the growth of polymer chains. In fact, large addition of acetic anhydride to the mixture creates chain ends unable to take part in polymerization.

3.7. Polymerization Mechanism. The ring-opening polymerization of $\mathrm{PCHO}$ can be achieved by addition of acetic anhydride via a cationic pathway. According to the obtained results, we propose a cationic mechanism for the polymerization initiated by protons provided by $\mathrm{H}_{3} \mathrm{PW}_{12} \mathrm{O}_{40}$ (Scheme 2). Initiation. The first stage is the protonation of acetic anhydride by $\mathrm{H}_{3} \mathrm{PW}_{12} \mathrm{O}_{40}$, leading to the formation of acetyl polyoxometalate salt. Then there is a nucleophilic attack of the oxygen of cyclohexene oxide on the carbon atom of the acetyl species. The formed oxonium ion undergoes a nucleophilic attack on the carbon by the oxygen of the cyclohexene oxide of the chains in growth. Propagation. In this stage, the protonated oxonium ion undergoes a nucleophilic attack by a molecule of cyclohexene oxide. Termination. The last stage is a nucleophilic attack of the oxygen of the acetic acid formed in the first stage on the carbon in alpha of positively charged oxygen of the chains in growth.

\section{Conclusions}

From the results it can be concluded that Keggin-type heteropolyacid $\left(\mathrm{H}_{3} \mathrm{PW}_{12} \mathrm{O}_{40}\right)$ is an effective catalyst of the ringopening polymerization of cyclohexene oxide owing to its strong Brønsted acidity.

The microstructure of the resulting $\mathrm{PCHO}$ is different from that prepared over clay and alumina alkoxide catalysts. The low $T_{\mathrm{g}}$ value of the $\mathrm{PCHO}$ is due to the microstructure but not to molecular weight. Contrary to most polymerization reactions, the molecular weight and the yield increase with the increase of the temperature.

The decrease in the molecular weight with the increase of the amount of catalyst might be due to the increase of the amount of water which increased with the increase of catalyst amount or to the increase of the number of initiating active sites $\left(\mathrm{H}^{+}\right)$which increases the number of chains at the expense of the length of the chains. 
Controlled low molecular weight of the $\mathrm{PCHO}$ over $\mathrm{H}_{3} \mathrm{PW}_{12} \mathrm{O}_{40}$ can find various applications. It can be used for preparing soft segments for thermoplastic elastomers.

The use of $\mathrm{H}_{3} \mathrm{PW}_{12} \mathrm{O}_{40}$ as a solid acid catalyst instead of the usual soluble inorganic acids is a contribution to a reduction of waste.

\section{Conflict of Interests}

The authors declare that there is no conflict of interests regarding the publication of this paper.

\section{Acknowledgment}

The authors extended their appreciation to the Deanship of Scientific Research at King Saud University for funding the work through the research group Project no. RGP-VPP-116.

\section{References}

[1] O. Nuyken and S. D. Pask, "Ring-opening polymerization-an introductory review," Polymers, vol. 5, no. 2, pp. 361-403, 2013.

[2] A. Yahiaoui, M. Belbachir, J. C. Soutif, and L. Fontaine, "Synthesis and structural analyses of poly (1,2 cyclohexene oxide) over solid acid catalyst," Materials Letters, vol. 59, no. 7, pp. 759-767, 2005.

[3] Y. Zhang, D. Wang, K. Wurst, and M. R. Buchmeiser, "Ringopening polymerization of cyclohexene oxide by a novel dicationic palladium catalyst," Designed Monomers and Polymers, vol. 8, no. 6, pp. 571-588, 2005.

[4] H. Yasuda and E. Ihara, "Living polymerizations of polar and nonpolar monomers by the catalysis of organo rare earth metal complexes," Bulletin of the Chemical Society of Japan, vol. 70, no. 8, pp. 1745-1767, 1997.

[5] J. Ling, L. You, Y. Wang, and Z. Shen, "Ring-opening polymerization of cyclohexene oxide by recyclable scandium triflate in room temperature ionic liquid," Journal of Applied Polymer Science, vol. 124, no. 3, pp. 2537-2540, 2012.

[6] L. A. Allaoui and A. Aouissi, "Effect of the Brønsted acidity on the behavior of $\mathrm{CO}_{2}$ methanol reaction," Journal of Molecular Catalysis A: Chemical, vol. 259, no. 1-2, pp. 281-285, 2006.

[7] N. Mizuno and M. Misono, "Heterogeneous catalysis," Chemical Reviews, vol. 98, no. 1, pp. 199-217, 1998.

[8] I. V. Kozhevnikov, "Catalysis by heteropoly acids and multicomponent polyoxometalates in liquid-phase reactions," Chemical Reviews, vol. 98, no. 1, pp. 171-198, 1998.

[9] E. F. Kozhevnikova and I. V. Kozhevnikov, "A calorimetric study of the acidity of bulk and silica-supported heteropoly acid $\mathrm{H}_{3} \mathrm{PW}_{12} \mathrm{O}_{40}$," Journal of Catalysis, vol. 224, no. 1, pp. 164-169, 2004.

[10] M. Misono, I. Ono, G. Koyano, and A. Aoshima, "Heteropolyacids. Versatile green catalysts usable in a variety of reaction media," Pure and Applied Chemistry, vol. 72, no. 7, pp. 1305-1311, 2000.

[11] Y. Chen, G. L. Zhang, and H. Z. Zhang, "Control of molecular weight in tetrahydrofuran polymerization initiated by heteropolyacid," Journal of Applied Polymer Science, vol. 82, no. 2, pp. 269-275, 2001.

[12] A. Aouissi, "Cationic polymerization of 2.3 Dihydro-4H pyran using $\mathrm{H}_{3} \mathrm{PW}_{12} \mathrm{O}_{40}$ as a solid acid catalyst," Journal of Applied Polymer Science, vol. 117, no. 3, pp. 1431-1435, 2010.
[13] Q. Wu, L. Li, Y. Yu, and X. Tang, “The linear relations and living feature in cationic ring-opening copolymerization of epoxy/THF system," Colloid and Polymer Science, vol. 286, no. 6-7, pp. 761-767, 2008.

[14] A. Aouissi, S. S. Al-Deyab, and H. Al-Shehri, "Cationic ringopening polymerization of tetrahydrofuran with Keggin-type heteropoly compounds as solid acid catalysts," Chinese Journal of Polymer Science, vol. 28, no. 3, pp. 305-310, 2010.

[15] C. Rocchiccioli-Deltcheff, M. Fournier, R. Franck, and R. Thouvenot, "Vibrational investigations of polyoxometalates. 2. Evidence for anion-anion interactions in molybdenum(VI) and tungsten(VI) compounds related to the keggin structure," Inorganic Chemistry, vol. 22, no. 2, pp. 207-216, 1983.

[16] C. Rocchiccioli-Deltcheff and M. Fournier, "Catalysis by polyoxometalates. Part 3.-influence of vanadium(V) on the thermal stability of 12-metallophosphoric acids from in situ infrared studies," Journal of the Chemical Society, Faraday Transactions, vol. 87, no. 24, pp. 3913-3920, 1991.

[17] S. Suga and H. Aoyama, "Free-radical-induced polymerization of epoxides in the presence of maleic anhydride," Journal of Polymer Science Part A-1: Polymer Chemistry, vol. 7, no. 5, pp. 1237-1245, 1969.

[18] E. J. Goethals, "Cyclic oligomers in the cationic polymerization of heterocycles," Pure and Applied Chemistry, vol. 48, no. 3, pp. 335-341, 1976.

[19] P. Kubisa and S. Penczek, "Cationic activated monomer polymerization of heterocyclic monomers," Progress in Polymer Science, vol. 24, no. 10, pp. 1409-1437, 1999.

[20] T. A. Zevaco, J. K. Sypien, A. Janssen, O. Walter, and E. Dinjus, "Synthesis, structural characterisation of new oligomeric alkyl aluminium (2,2I-methylene- $p$-chloro-bisphenoxides) and application as catalysts in polymerisation reactions involving cyclohexene oxide," Journal of Organometallic Chemistry, vol. 692, no. 10, pp. 1963-1973, 2007.

[21] A. Aouissi, S. S. Al-Deyab, and H. Al-Shahri, "The cationic ring-opening polymerization of tetrahydrofuran with 12tungstophosphoric acid," Molecules, vol. 15, no. 3, pp. 1398-1407, 2010.

[22] M. I. Ferrahi and M. Belbachir, "Preparation of poly(oxybutyleneoxymaleoyl) catalyzed by a proton exchanged montmorillonite clay," Molecules, vol. 9, no. 11, pp. 968-977, 2004.

[23] T. Diao, X. Sun, R. Fan, and J. Wu, "Unexpected ring-opening reaction of aziridine with acetic anhydride in DMF," Chemistry Letters, vol. 36, no. 5, pp. 604-605, 2007. 

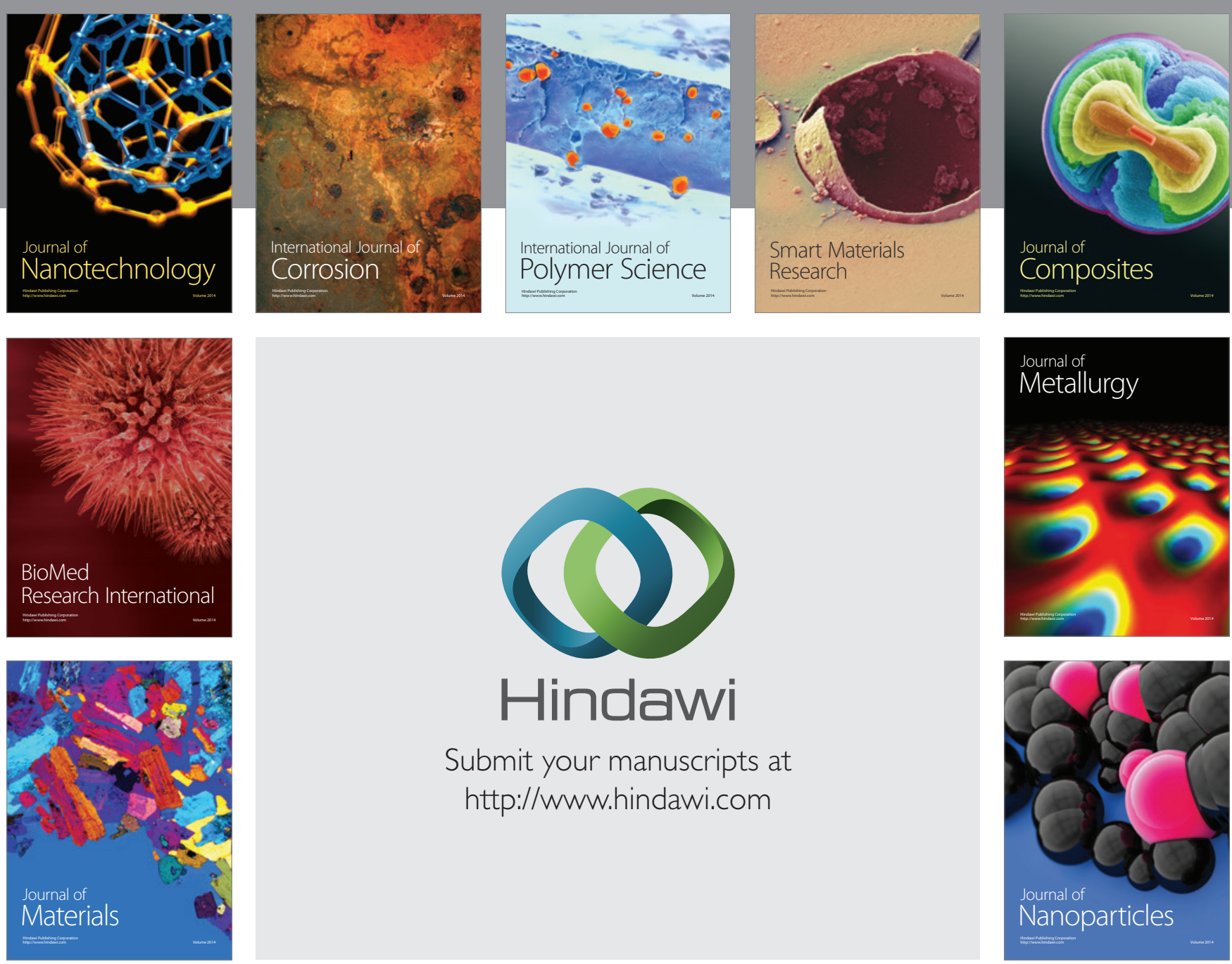

Submit your manuscripts at http://www.hindawi.com
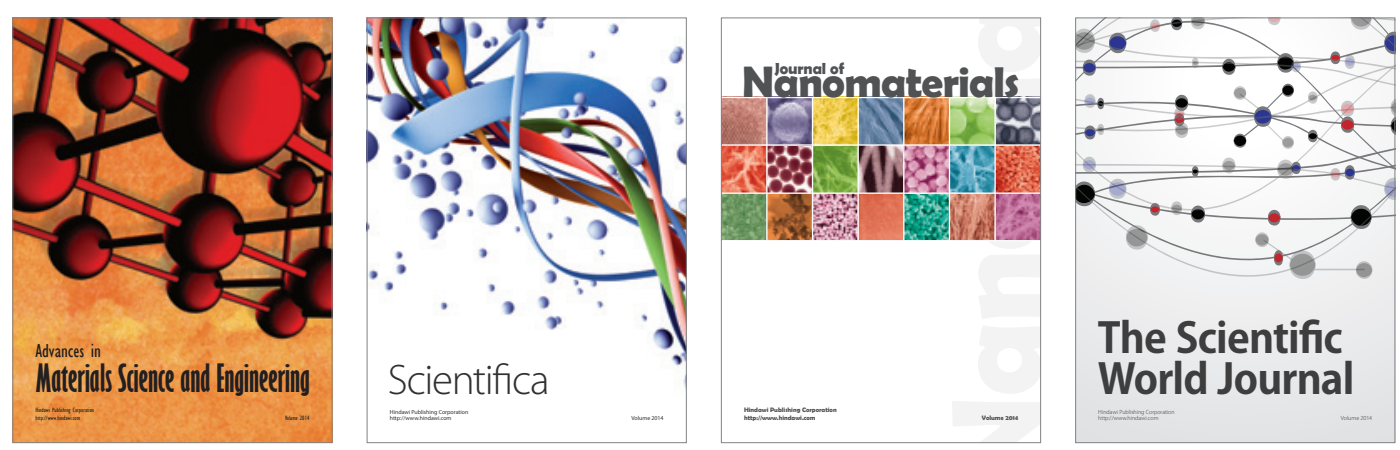

\section{The Scientific World Journal}
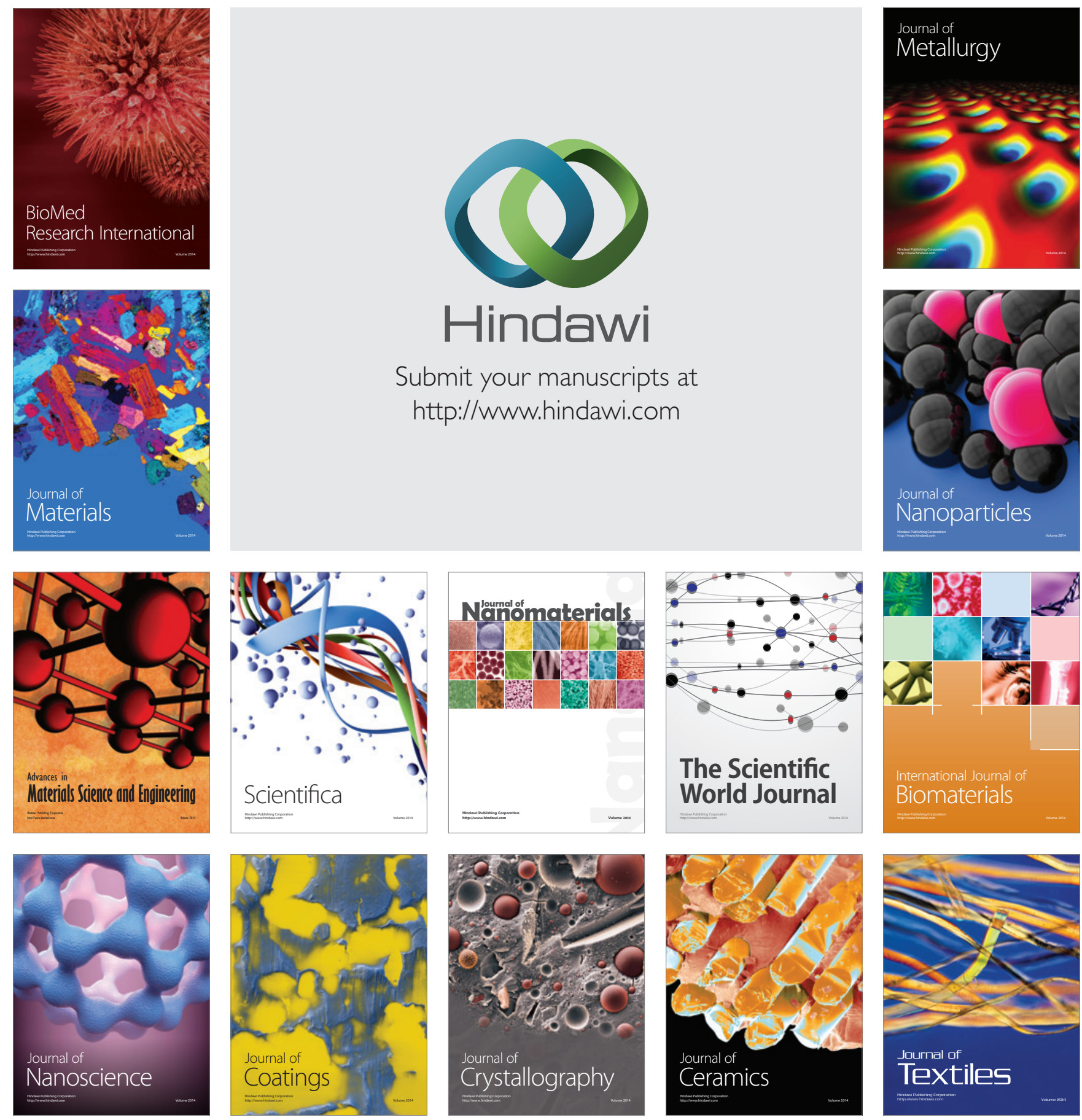